\title{
Evaluation of the neighborhood environment walkability scale in Nigeria
}

\author{
Adewale L Oyeyemi ${ }^{*}$, James F Sallis ${ }^{3}$, Benedicte Deforche ${ }^{2,4}$, Adetoyeje Y Oyeyemi ${ }^{1}$, Ilse De Bourdeaudhuij ${ }^{2}$ \\ and Delfien Van Dyck ${ }^{2,5}$
}

\begin{abstract}
Background: The development of reliable and culturally sensitive measures of attributes of the built and social environment is necessary for accurate analysis of environmental correlates of physical activity in low-income countries, that can inform international evidence-based policies and interventions in the worldwide prevention of physical inactivity epidemics. This study systematically adapted the Neighborhood Environment Walkability Scale (NEWS) for Nigeria and evaluated aspects of reliability and validity of the adapted version among Nigerian adults.

Methods: The adaptation of the NEWS was conducted by African and international experts, and final items were selected for NEWS-Nigeria after a cross-validation of the confirmatory factor analysis structure of the original NEWS. Participants ( $\mathrm{N}=386$; female $=47.2 \%)$ from two cities in Nigeria completed the adapted NEWS surveys regarding perceived residential density, land use mix - diversity, land use mix - access, street connectivity, infrastructure and safety for walking and cycling, aesthetics, traffic safety, and safety from crime. Self-reported activity for leisure, walking for different purposes, and overall physical activity were assessed with the validated International Physical Activity Questionnaire (long version).
\end{abstract}

Results: The adapted NEWS subscales had moderate to high test-retest reliability (ICC range $0.59-0.91$ ). Construct validity was good, with residents of high-walkable neighborhoods reporting significantly higher residential density, more land use mix diversity, higher street connectivity, more traffic safety and more safety from crime, but lower infrastructure and safety for walking/cycling and aesthetics than residents of low-walkable neighborhoods. Concurrent validity correlations were low to moderate $(r=0.10-0.31)$ with residential density, land use mix diversity, and traffic safety significantly associated with most physical activity outcomes.

Conclusions: The NEWS-Nigeria demonstrated acceptable measurement properties among Nigerian adults and may be useful for evaluation of the built environment in Nigeria. Further adaptation and evaluation in other African countries is needed to create a version that could be used throughout the African region.

Keywords: Built environment, Physical activity, Measurements, Psychometric, Africa

\section{Introduction}

Physical inactivity is the fourth leading cause of death worldwide, with most of these deaths occurring in developing countries [1-3]. Increasing physical activity is one of four strategies recommended by the United Nations to reduce global epidemics of non-communicable diseases (NCD) [4]. The World Health Organization [5] and numerous authoritative groups [6-10] recommended

\footnotetext{
* Correspondence: alaoyeyemi@yahoo.com

'Department of Physiotherapy, College of Medical Sciences, University of Maiduguri, Maiduguri, Nigeria

Full list of author information is available at the end of the article
}

environmental and policy interventions as viable strategies to improve physical activity and prevent obesity worldwide. The theoretical framework for understanding such interventions is the ecological model that is based on the principle that health behaviors are influenced by multiple levels, including individual, social/cultural, built environment, and policy [11]. Such models have provided the conceptual basis for studying environmental correlates of physical activity and other health-related behaviors because these environmental factors can affect large populations over long periods of time [12], and can provide an empirical basis for interventions. In this
C Biomed Central 
context, research linking the built environment with physical activity has increased rapidly in recent years $[10,13-15]$, and is now an international priority [16,17].

In the developed countries of North America, Australia and Europe, consistent findings have emerged that people who live in neighborhoods with supportive built environment features like high residential density, street connectivity, proximal access to destinations, good aesthetics and availability of infrastructures and facilities are more physically active than those living in neighborhoods with unsupportive environmental features [14-16,18,19]. Africa is the only continent for which evidence on the association between the built environment and physical activity is lacking [16,20,21], and questions remain about the applicability of surveys constructed in developed countries to the local contexts in Africa [22]. To address this problem, there have been recent calls for investigators in Africa to adapt built environment measures to African contexts [17,21,22]. If evidence- based environmental interventions are to be developed in the African region, there is the need to first tailor environmental measures to African countries and then use the adapted measures to identify promising environmental correlates of physical activity in these countries. Understanding environmental correlates of physical activity and other health behaviors in Africa has implications to inform international evidence-based and countryspecific physical activity policies and interventions to help prevent obesity and other chronic diseases [21]. Such interventions would not only help reduce the effect of growing epidemics of inactivity in developing countries [23], but also contribute to effective global prevention of non-communicable diseases that are high in developed countries and growing rapidly in low and middle income countries [1-3,5]. However, valid measures of theoretically relevant environmental variables applicable to Africa are needed for research to progress and for the development of an applicable evidence base in African countries.

The Neighborhood Environment Walkability Scale (NEWS) is a frequently used questionnaire for assessing perceived attributes of the neighborhood environment for physical activity [24-28]. The NEWS is being used by the International Physical Activity and Environment Network (IPEN) for cross-country analyses of built environment and physical activity relationships [21,29]. It is a reliable and valid instrument [24,26,30-32], that has been tested internationally and translated into many languages [18,25,26,32-34]. However, the NEWS was developed in the USA, and its applicability to other environments may be limited due to differences in culture and environmental features [32,35]. African urban environments are different from those in the developed countries. Most African urban neighborhoods have diverse terrains, land use, infrastructures, transportation and road designs that may not be adequately captured by measures constructed in the developed countries. While prevalence of attributes characterizing a Western lifestyle like high car ownership, dog walking and having pets appear to be lower in African countries like Nigeria, high crime rates including assault, rape, robbery, burglary and motor vehicle theft are more prominent compared to western developed countries [36]. Though adaptation of surveys is essential there is value in retaining items and constructs that will allow for comparisons of findings across countries [21]. Therefore, adaptation and evaluation of environmental measures constructed elsewhere is required as a first step before such measures can be used to adequately evaluate built environments in Africa.

Since a major goal of IPEN is to represent the worldwide variation in built environment, psychometric evaluation of NEWS in sub-Saharan African countries would allow for international and cross-national comparison of findings on environmental correlates of physical activity research. It is particularly important for research in this field of study to establish measures of both internationally comparable environmental variables and those of particular relevance to the local environment in Africa. Because Nigeria is the most populous country in Africa with culture and languages similar to most sub-Saharan African countries, it is a good choice to evaluate the feasibility of using the NEWS for measuring built environment in this country. NEWS-Nigeria has potential for advancing physical activity research on environmental correlates of physical activity in other African countries. The aim of the present study was to systematically adapt the NEWS to Nigeria and evaluate aspects of reliability and validity of the adapted NEWS among adults in Nigeria.

\section{Methods \\ Procedures}

Participants were recruited from two cities (Maiduguri and Ilorin) in Nigeria. Maiduguri is the largest and capital city of the state of Borno, located in NorthEastern Nigeria and about $920 \mathrm{~km}$ North of Abuja, the capital city of Nigeria. The city of Maiduguri has about 749,000 inhabitants and Borno state covers an area of $72,609 \mathrm{~km}^{2}$ with a population density of about 57 inhabitants per $\mathrm{km}^{2}$ [37]. The state of Borno shares boundary with Cameroon, Chad and Niger Republic. Ilorin is the largest and capital city of the State of Kwara, located in the Central part of Nigeria and about $485 \mathrm{~km}$ South of Abuja. The city of Ilorin has about 782,000 inhabitants and the state of Kwara covers an area of $35,705 \mathrm{~km}^{2}$ with a population density of about 66 inhabitants per $\mathrm{km}^{2}$ [37]. Both Maiduguri and Ilorin have neighborhoods located in the inner city and Government Reserved Areas 
(GRA) or new layout areas that have a diversity of housing patterns, land use mix and access and street characteristics. Consistent with high walkability neighborhood characteristics [33,38,39], neighborhoods in the inner city in Maiduguri and Ilorin have a high concentration of multiple family residences, non- residential land uses (small retail stores, shops, local markets and places of worship) and streets with short block length with many alternative routes to destinations. Neighborhoods in the GRA/new layout areas are characterized by predominantly single family homes, few non- residential land uses and streets with longer block length with fewer alternative routes to destinations, consistent with low walkability neighborhood features [33,38,39]. However, the inner city areas in both cities are mostly low socioeconomic status (SES) areas, while the GRA/new layout areas are mostly high SES [40].

A purposive sample of adults was drawn from both cities to represent the diversity of neighborhood environments. In Maiduguri, participants were recruited from eight previously identified neighborhoods (four each in the inner city and GRA/new layout) that have been stratified into high-walkable/low SES and lowwalkable/high SES for research purposes [41]. In Ilorin, participants were recruited from 6 non-adjacent neighborhoods that are different in walkability/SES categories (three each in the inner city and GRA/new layout) as identified by the research team (ALO, AYO) and a local urban planning expert. Specifically, the walkability components, defined as residential density, mixed land use and connectivity from previous studies [33,38,39], were used to identify the high- and low-walkable neighborhoods used for participants' recruitment in the present study. The research team and the expert made summary judgments based on direct observation, local knowledge and professional background in assigning neighborhoods into the two walkability categories.

Sample size was determined using a more conservative effect size (effect size statistic $[d=]$ 0.45) than that found in a previous study [24]. We determined that 77 participants from each neighborhood stratum (high- walkable/ low SES [inner city] and low- walkable/high SES [GRA/ new layout]) in each city was needed to detect a moderate to large effect size with more than $80 \%$ power [42]. Recruitment continued until approximately 80 individuals from each neighborhood type (low and high walkability) in each city had completed the survey and had provided physical activity data (Table 1 ).

Contact was attempted with 225 individuals in Maiduguri (108 in the inner city and 117 in the government reserved areas/new layout). Among the individuals contacted, 80 in both the inner city and government reserved areas/new layout neighborhoods (respectively $74.1 \%$ and $68.4 \%$ ), completed and provided a usable test- retest survey. In Ilorin, 259 individuals (125 in the inner city and 134 in the GRA/new layout) were contacted for the study, and $105(84.0 \%)$ in the inner city and 101 (75.4\%) in the GRA/new layout areas provided completed and usable surveys. All participants in the two cities were recruited directly from their homes in the identified neighborhoods. Eligibility criteria included: (1) living within the identified neighborhood categories in the last 12 months, (2) being 20-65 years old, (3) not having any disability that prevented independent walking and (4) being able and willing to complete a written survey in English language, which is the official language in Nigeria.

To assess test-retest reliability, only participants in Maiduguri city were invited to complete the adapted NEWS questionnaire twice, with an interval of two weeks. Test-retest reliability could not be conducted in the city of Ilorin due to logistical difficulty of recontacting participants. Construct validity was assessed by comparing scores on the NEWS among residents living in neighborhoods that differed in walkability in both Maiduguri and Ilorin, similar to approaches in prior studies [24,33]. Concurrent validity was studied by investigating the relationships between NEWS measures and outcomes from the International Physical Activity Questionnaire (IPAQ)-long form. Although transport-related and leisure-time selfreported walking are theoretically hypothesized to be associated with variables assessed in NEWS and are often used as the validity criterion for NEWS measures [18,30], leisure time moderate-to-vigorous physical activity (MVPA), total MVPA and total physical activity also were included as criterion variables for concurrent validity in the present study because guidelines for sufficient health-enhancing physical activity are often based on leisure time MVPA and total physical activity [43-45]. It is therefore important to understand how the NEWS measures relate to various physical activity outcomes of adults in an understudied region like Africa.

Demographic characteristics of participants were obtained on the first day of contact. All participants provided informed consent, and the study was approved by the ethics committee of the University of Maiduguri Teaching Hospital, (ADM/TH/EC/75).

\section{Measures}

\section{Neighborhood environment walkability scale}

The neighborhood environment walkability scale (NEWS) was adapted to assess neighborhood environment characteristics relevant to sub-Saharan Africa. The research team (ALO, JFS, AYO) and a group of public health scientists from Africa and the IPEN center in the United States coordinated the adaptation of the NEWS for use in Nigeria. The adaptation process was similar to that utilized for the Nigerian physical activity neighborhood environment scale 
Table 1 Descriptive characteristics of the sample $(\mathrm{N}=386)$

\begin{tabular}{|c|c|c|c|c|}
\hline & Maiduguri sample $(n=280)$ & Ilorin sample $(n=206)$ & Statistics & p-value \\
\hline Gender $(n, \%)$ & & & $1.09+$ & 0.308 \\
\hline Female & $90(50.0)$ & $92(44.7)$ & & \\
\hline Male & $90(50.0)$ & $114(55.3)$ & & \\
\hline Age (years) Mean ( \pm SD) & $35.6 \pm 10.3$ & $36.7 \pm 3.9$ & $1.16 \neq$ & 0.248 \\
\hline Marital status $(n, \%)$ & & & $0.49+$ & 0.537 \\
\hline Married & $106(58.9)$ & $114(55.3)$ & & \\
\hline Not married & $74(41.1)$ & $92(44.7)$ & & \\
\hline Tribe/ethnicity $(n, \%)$ & & & $307.15+$ & $<0.001^{*}$ \\
\hline Hausa/Fulani & $21(11.7)$ & $5(2.4)$ & & \\
\hline Igbo & $8(4.4)$ & $5(2.4)$ & & \\
\hline Yoruba & $10(5.6)$ & $193(93.7)$ & & \\
\hline Kanuri/Shuwa & $44(24.4)$ & $0(0.0)$ & & \\
\hline Other & $97(53.9)$ & $3(1.5)$ & & \\
\hline Educational level $(n, \%)$ & & & $31.92+$ & $0.001^{*}$ \\
\hline >Secondary School & $111(62.7)$ & $149(72.7)$ & & \\
\hline Secondary School & $38(21.5)$ & $55(26.8)$ & & \\
\hline <Secondary School & $28(15.8)$ & $1(0.5)$ & & \\
\hline Occupation $(n, \%)$ & & & $3.99+$ & 0.136 \\
\hline White collar & $72(40.0)$ & $70(34.3)$ & & \\
\hline Blue collar & $45(25.0)$ & $70(34.3)$ & & \\
\hline Unemployed & $63(35.0)$ & $64(31.4)$ & & \\
\hline BMI Prevalence $(n, \%)$ & & & $6.18+$ & 0.103 \\
\hline Underweight & $14(7.8)$ & $8(3.9)$ & & \\
\hline Normal weight & $107(59.4)$ & $142(68.9)$ & & \\
\hline Overweight & $51(28.3)$ & $52(25.2)$ & & \\
\hline Obese & $8(4.4)$ & $4(1.9)$ & & \\
\hline BMI $\left(\mathrm{Kg} / \mathrm{m}^{2}\right)$ Mean $( \pm \mathrm{SD})$ & $23.8 \pm 3.9$ & $23.8 \pm 2.7$ & $0.01 \neq$ & 0.995 \\
\hline Income (Naira) (n,\%) & & & $0.32+$ & 0.957 \\
\hline$<15,000$ & $49(33.1)$ & $59(32.2)$ & & \\
\hline $16,000-45,000$ & $50(33.8)$ & $62(33.9)$ & & \\
\hline $46,000-90,000$ & $30(20.3)$ & $41(22.4)$ & & \\
\hline$>90,000$ & $19(12.8)$ & $21(11.5)$ & & \\
\hline Neighborhood type (n,\%) & & & $0.04+$ & 0.849 \\
\hline Low SES/high walkable & $90(50.0)$ & $105(51.0)$ & & \\
\hline High SES/low walkable & $90(50.0)$ & $101(49.0)$ & & \\
\hline
\end{tabular}

$t_{-}$Values based on Chi-Square Statistics.

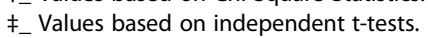

*- Significant difference between samples $(p<0.05)$.

BMI- Body Mass Index.

[46] and the Assessing Levels of Physical Activity (ALPHA) questionnaire in Europe [35], and was based on empirical literature from the transportation planning and urban planning fields [38]. Since the goal of the adaptation was to retain as many original concepts and items as possible but to express them in ways that are appropriate for the local culture and environment in sub-Sahara Africa, the final adaptation of the NEWS included all items of the original instrument [24] in their original or slightly modified form, with 18 additional items describing 
Table 2 Nigerian-NEWS: answer frequencies, mean scores, and test-retest reliability scores $(\mathrm{N}=386)$

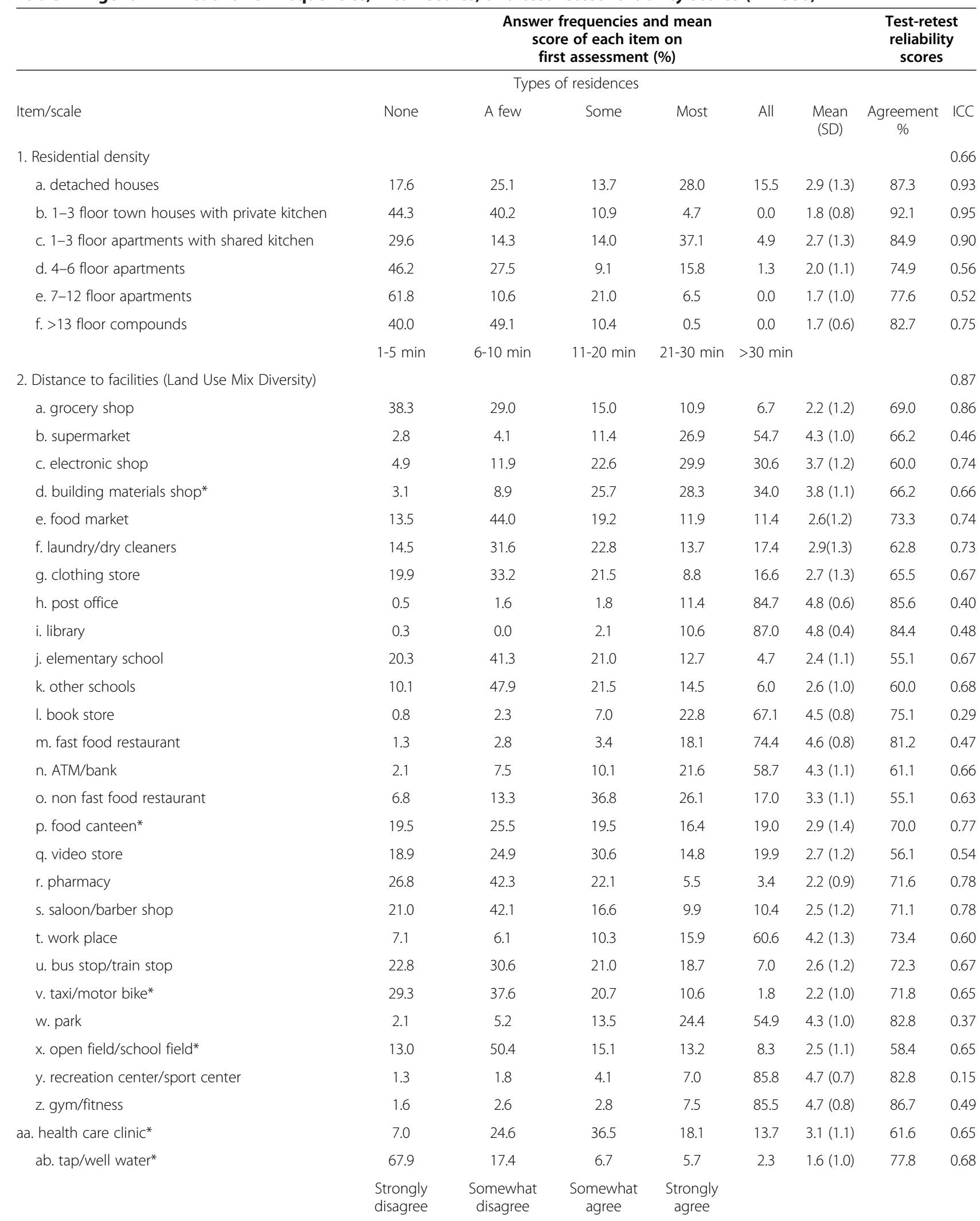


Table 2 Nigerian-NEWS: answer frequencies, mean scores, and test-retest reliability scores $(\mathbf{N}=\mathbf{3 8 6})($ Continued)

\begin{tabular}{|c|c|c|c|c|c|c|c|}
\hline \multicolumn{7}{|l|}{ 3. Land use mix access } & 0.76 \\
\hline a. possible to do shopping at local stores & 11.2 & 14.8 & 34.9 & 39.1 & $3.0(0.9)$ & 66.1 & 0.55 \\
\hline b. shops within easy walking distance & 14.2 & 10.9 & 40.7 & 34.2 & $2.9(1.0)$ & 74.4 & 0.67 \\
\hline c. many places in walking distance & 17.1 & 23.1 & 36.3 & 23.6 & $2.7(1.0)$ & 65.6 & 0.53 \\
\hline d. easy to walk to transit stop & 5.7 & 18.7 & 37.6 & 38.1 & $3.1(0.9)$ & 71.2 & 0.74 \\
\hline e. bad roads/poor drainages* & 26.2 & 24.2 & 18.7 & 30.9 & $2.5(1.2)$ & 66.7 & 0.80 \\
\hline \multicolumn{7}{|l|}{ 4. Street connectivity } & 0.72 \\
\hline a. distance between intersections is short & 21.0 & 13.8 & 35.8 & 29.4 & $2.7(1.1)$ & 73.4 & 0.72 \\
\hline b. many four-way intersections & 26.4 & 23.1 & 29.8 & 20.7 & $2.5(1.1)$ & 72.2 & 0.77 \\
\hline c. many alternative routes & 9.6 & 17.1 & 29.0 & 44.3 & $3.1(0.9)$ & 67.2 & 0.55 \\
\hline \multicolumn{7}{|l|}{ 5. Infrastructure and safety for walking/cycling } & 0.59 \\
\hline a. sidewalks on most streets & 46.9 & 25.9 & 20.2 & 7.0 & $1.9(0.9)$ & 84.5 & 0.80 \\
\hline b. sidewalks well maintained & 63.5 & 28.8 & 4.4 & 3.3 & $1.5(0.7)$ & 85.0 & 0.74 \\
\hline c. bicycle/pedestrian trails nearby & 61.8 & 26.0 & 7.3 & 4.9 & $1.6(0.8)$ & 86.6 & 0.37 \\
\hline d. sidewalks separated by parked cars & 39.8 & 28.1 & 21.1 & 10.9 & $2.0(1.0)$ & 80.5 & 0.53 \\
\hline e. sidewalks separated by grass/dirt strip & 32.4 & 24.6 & 29.3 & 13.7 & $2.2(1.1)$ & 81.1 & 0.68 \\
\hline f. safe to ride a bicycle & 17.4 & 18.4 & 47.3 & 16.9 & $2.6(0.9)$ & 62.8 & 0.47 \\
\hline g. streets well lit at night & 42.6 & 19.0 & 25.7 & 12.7 & $2.1(1.1)$ & 72.7 & 0.72 \\
\hline $\begin{array}{l}\text { h. walkers and cyclists easily seen by people in } \\
\text { homes }\end{array}$ & 53.9 & 20.3 & 13.3 & 12.5 & $1.8(1.1)$ & 73.5 & 0.87 \\
\hline i. crosswalks and pedestrian signals available & 82.1 & 12.7 & 3.4 & 1.8 & $1.3(0.6)$ & 91.7 & 0.05 \\
\hline j. crosswalks are safe & 80.8 & 14.8 & 3.9 & 0.5 & $1.2(0.5)$ & 89.4 & 0.01 \\
\hline k. facilities for bicycle use (lanes etc.) available* & 62.0 & 25.5 & 6.5 & 6.0 & $1.6(0.9)$ & 89.4 & 0.52 \\
\hline I. walk path on most streets* & 6.5 & 21.0 & 42.5 & 30.1 & $2.9(0.9)$ & 76.1 & 0.76 \\
\hline m. walk path not obstructed* & 7.5 & 38.4 & 30.9 & 23.1 & $2.7(0.9)$ & 68.3 & 0.53 \\
\hline n. walk path separated from road* & 20.0 & 24.2 & 35.8 & 20.0 & $2.6(1.0)$ & 73.3 & 0.70 \\
\hline o. curb cut ramps from sidewalk to road* & 46.4 & 13.7 & 29.0 & 10.8 & $2.0(1.1)$ & 88.8 & 0.20 \\
\hline $\begin{array}{l}\text { p. have to cross crowded streets to get to } \\
\text { places* }^{*}\end{array}$ & 53.8 & 36.4 & 8.3 & 1.6 & $1.6(0.7)$ & 74.9 & 0.68 \\
\hline $\begin{array}{l}\text { q. islands for pedestrians in middle of major } \\
\text { roads * }\end{array}$ & 65.1 & 18.0 & 12.2 & 4.7 & $1.6(0.9)$ & 84.4 & 0.85 \\
\hline $\begin{array}{l}\text { r. pedestrian signals give enough time to cross } \\
\text { street* }\end{array}$ & 83.4 & 11.2 & 3.1 & 2.3 & $1.2(0.6)$ & 96.1 & 0.02 \\
\hline \multicolumn{7}{|l|}{ 6. Aesthetics } & 0.91 \\
\hline a. presence of trees & 28.0 & 20.2 & 23.8 & 28.0 & $2.5(1.2)$ & 75.0 & 0.85 \\
\hline b. trees give shade & 35.0 & 19.2 & 27.7 & 18.1 & $2.3(1.1)$ & 74.5 & 0.83 \\
\hline c. many interesting things to look at & 35.0 & 17.4 & 25.4 & 22.3 & $2.4(1.2)$ & 71.8 & 0.81 \\
\hline d. neighborhood is free from litter & 29.1 & 21.0 & 21.0 & 28.8 & $2.5(1.2)$ & 74.6 & 0.85 \\
\hline e. attractive natural sights & 51.7 & 26.2 & 12.5 & 9.6 & $1.8(0.9)$ & 71.1 & 0.31 \\
\hline f. attractive buildings & 22.0 & 23.3 & 23.1 & 31.6 & $2.6(1.1)$ & 62.8 & 0.50 \\
\hline \multicolumn{7}{|l|}{ 7. Traffic safety } & 0.65 \\
\hline a. much traffic on street I live & 52.0 & 31.9 & 11.2 & 5.0 & $1.7(0.9)$ & 82.0 & 0.74 \\
\hline b. much traffic on nearby streets & 39.8 & 34.1 & 19.3 & 6.3 & $1.9(0.9)$ & 73.0 & 0.75 \\
\hline c. speed of traffic on street I live is slow & 13.3 & 21.6 & 29.7 & 35.4 & $2.9(1.0)$ & 78.0 & 0.80 \\
\hline
\end{tabular}


Table 2 Nigerian-NEWS: answer frequencies, mean scores, and test-retest reliability scores $(\mathbf{N}=\mathbf{3 8 6})(\mathrm{Continued})$

\begin{tabular}{|c|c|c|c|c|c|c|c|}
\hline d. speed of traffic on nearby streets is slow & 26.0 & 33.6 & 22.1 & 18.2 & $2.3(1.1)$ & 70.8 & 0.76 \\
\hline e. drivers exceed speed limits & 28.4 & 28.4 & 28.1 & 15.1 & $2.3(1.1)$ & 66.8 & 0.60 \\
\hline f. a lot of exhaust fumes & 40.9 & 27.1 & 18.0 & 14.1 & $2.1(1.1)$ & 71.5 & 0.41 \\
\hline $\begin{array}{l}\text { g. cars going across sidewalks make it difficult } \\
\text { to walk* }\end{array}$ & 36.5 & 34.9 & 19.3 & 9.4 & $2.0(0.9)$ & 74.8 & 0.68 \\
\hline \multicolumn{8}{|l|}{ 8. Safety from crime } \\
\hline a. high crime rate & 46.5 & 23.6 & 18.2 & 11.7 & $2.0(1.1)$ & 82.1 & 0.82 \\
\hline b. unsafe to walk during day & 55.6 & 38.2 & 4.7 & 1.6 & $1.5(0.7)$ & 85.0 & 0.61 \\
\hline c. unsafe to walk at night & 33.0 & 24.9 & 20.0 & 22.1 & $2.3(1.1)$ & 69.9 & 0.68 \\
\hline d. presence of gangs induces unsafe feeling* & 43.6 & 24.7 & 16.4 & 15.3 & $2.0(1.1)$ & 76.6 & 0.70 \\
\hline \multicolumn{8}{|l|}{ 9. Single items } \\
\hline a. parking near local shops is difficult & 25.2 & 27.5 & 35.3 & 11.9 & $2.3(0.9)$ & 58.9 & 0.53 \\
\hline b. streets are hilly & 56.0 & 26.2 & 10.1 & 7.8 & $1.7(0.9)$ & 91.2 & 0.48 \\
\hline c. streets do not have many cul-de-sacs & 20.7 & 27.5 & 21.8 & 30.1 & $2.6(1.1)$ & 70.6 & 0.66 \\
\hline d. many canyons/hillsides in neighborhood & 56.0 & 22.3 & 12.4 & 9.3 & $1.8(0.9)$ & 91.6 & 0.53 \\
\hline $\begin{array}{l}\text { e. see and speak to other people while walking } \\
\text { in neighborhood }\end{array}$ & 19.7 & 16.1 & 34.3 & 29.9 & $2.7(1.1)$ & 64.3 & 0.81 \\
\hline f. many unattended domestic animals* & 30.6 & 15.3 & 16.4 & 37.7 & $2.6(1.3)$ & 78.0 & 0.86 \\
\hline
\end{tabular}

ICC = intra class coefficient.

* Specific African items added to NEWS.

features of the environment relevant to sub-Sahara Africa (see Table 2).

The adapted NEWS survey consists of 83 items that assessed the following perceived environmental characteristics: a) residential density (6 items); b) proximity to non-residential land uses (land use mix - diversity) (28 items); ease of access to nonresidential uses (land use mix - access) (5 items); street connectivity (3 items); infrastructure and safety for walking and cycling (18 items); aesthetics (6-items); traffic safety (7 items) and safety from crime (4 items). Six other items were analyzed as single items: parking near local shops is difficult; streets in the neighborhood are hilly; streets in the neighborhood do not have many cul-de-sacs; there are many canyons/hillsides in the neighborhood that limit number of routes; I can see and speak to other people while walking in the neighborhood; there are many unattended domestic animals in the neighborhood. Calculation of the subscales of the adapted NEWS (hereafter called NEWS-Nigeria) and selection of the single items were based on methods proposed by Cerin and colleagues after a cross-validation of the confirmatory factor analysis structure of NEWS [31]. The 18 new items were added to specific scales, based on the content of the items: 6 items were added to the land use mix diversity scale, 1 item to 'land use mix access', 8 items to 'infrastructure and safety for walking and cycling', 1 item to 'traffic hazards', and 1 item to 'safety from crime'. The presence of unattended domestic animals in the neighborhood was scored as a single item. After adding these items, Cronbach alphas $(\alpha)$ were calculated for the adjusted scales. The $\alpha$ values ranged from 0.64 (traffic hazards) to 0.86 (safety from crime), showing good internal consistency of the scales. Scoring details and a digital version of the original NEWS can be found on http:// sallis.ucsd.edu/measures.

All subscales and single items, with the exception of residential density and land use mix-diversity, were rated on a 4-point Likert scale. Residential density items asked about the presence of various types of neighborhood residences, from single-family detached homes to 13-story or higher apartments (more than 13 apartment/rooms for multiple families), with a response range of 1 (none) to 5 (all). Residential density items were weighted relative to the average density of single-family detached residences (e.g., 7- to- 12 story apartments were considered to be 50 times more person-dense than single family residences), and weighted values were summed to create a residential density subscale score $[24,30]$. Land use mixdiversity was assessed by the walking proximity from homes to various types of destinations, with response ranging from 1- to 5-min walking distance (coded as 5) to $>30$-min walking distance (coded as 1 ). Higher scores on land use mix-diversity indicated closer average proximity (higher walkability).

\section{Self- reported walking and physical activity}

The long version of the International Physical Activity Questionnaire (IPAQ-long) was used to assess participants' self-reported physical activity and walking for 
different purposes. The questionnaire assessed frequency (number of days in the last 7 days) and duration (hours and minutes per day) of physical activity in four domains (work, transportation, recreation and household) and of motorized transport. The IPAQ was used to compute weekly minutes of walking for recreation, cycling for transport, walking for transport and leisure time moderate-to-vigorous physical activity (MVPA). Leisure time MVPA was obtained by summing minutes per week of moderate physical activity and vigorous physical activity during leisure-time. Total MVPA was computed by summing the total min/week of reported physical activity of moderate and vigorous- intensities across all four domains. For total physical activity, the total min/ week of activities in each domain were summed (total work + total transport + total domestic and garden + total leisure-time min/week scores) to gain an overall estimate of physical activity in a week (www.ipaq.ki.se). The IPAQ-long has good reliability (intra-class range from 0.46 to 0.96 ) and fair-to-moderate criterion validity in a 12 -country study $(\rho=0.30)$, comparable to other selfreport measures [47]. Acceptable intraclass correlation coefficients ranging from 0.60 to 0.82 have been reported for the transportation and leisure time physical activity of IPAQ [48], including the walking items used in the present study.

\section{Sociodemographic characteristics}

Information on age, gender, marital status, religion, income, educational level and employment status were elicited from the participants. Marital status was classified as married or not married. Educational level was classified as more than secondary school education, secondary school education, and less than secondary school education. Employment status was classified into white collar (government, private employed), blue collar (selfemployed, trader, artisan etc.) and unemployed (homemaker, student, retired, or unable to find job). Income was categorized into 4 groupings based on NAIRA/ month $(15000$ NAIRA $\approx 100$ US Dollars). Participants' ethnicity/tribe was classified as Hausa/Fulani, Yoruba, Ibo, Kanuri/Shuwa and other. Height and weight was measured using a digital scale and stadiometer. Body mass index (BMI) was calculated as body weight divided by the square of height $\left(\mathrm{kg} / \mathrm{m}^{2}\right)$. The World Health Organization principal cutoff points for BMI were used to create the categories: underweight $\left(<18.5 \mathrm{~kg} / \mathrm{m}^{2}\right)$, normal weight $\left(18.5-<25 \mathrm{~kg} / \mathrm{m}^{2}\right)$, overweight (25$\left.<30 \mathrm{~kg} / \mathrm{m}^{2}\right)$ and obese $\left(\geq 30 \mathrm{~kg} / \mathrm{m}^{2}\right)$ [49].

\section{Statistical analysis}

Descriptive statistics are presented for the sociodemographic characteristics of all participants. Differences in sociodemographic variables between cities and neigh- borhood walkability/SES were examined with independent $t$-test procedures for continuous variables and with Chi-square tests for dichotomous variables.

To evaluate the test-retest reliability of the adapted NEWS-Nigeria, one-way model single-measure intraclass correlation coefficients (ICC) were calculated to test individual items. To test NEWS scale scores computed from multiple items, the single-measure ICC was also computed. ICC represents the proportion of total variance in a set of values that is attributable to between-subjects variability, with the remaining proportion attributable to error. ICC estimates $>0.75$ were considered as good reliability scores, between 0.50 and 0.75 as moderate reliability and $<0.50$ as poor reliability [50]. Proportion of agreement was also calculated to measure the proportion of occasions that individuals gave the same score. Proportion of agreement above 0.70 was considered high [51].

To assess the construct validity of NEWS-Nigeria, general linear model procedures were used to conduct multivariate ANCOVA tests (adjusting for residents' age, gender, income, and educational level) to analyze neighborhood differences (high SES/low walkability vs low SES/high walkability) in environmental scales. To assess the concurrent validity of NEWS-Nigeria, Pearson correlations were calculated between environmental variables (scales and single items) and IPAQ measurements. All analyses were performed using IBM SPSS Statistics 19.

\section{Results}

The descriptive characteristics of the sample $(\mathrm{N}=386)$ are reported in Table 1 . No differences were found between the samples from both cities for gender, age, marital status, occupation, body mass index, income and neighborhood types. Significant differences were found for education, with more participants with higher education from Ilorin than Maiduguri $(p<0.001)$. The prevalence of overweight or obesity in both cities was comparable with the Nigerian population (23.9\%- 38.6\% overweight or obese, on population level) [52]. However, participants from both cities were somewhat higher educated compared with the Nigerian population (34.3\% with higher education, on population level) [52]. The unemployed were over-represented in both cities' subsamples, compared with the unemployment distribution of the general population in Nigeria $(19.7 \%$, on a population level) [37].

\section{Test-retest reliability}

Table 2 shows the response frequency and mean score of each item on the first assessment of the adapted NEWS and its test-retest reliability scores. The ICCs of the sum scores of each of the eight subscales ranged from 0.59 to 0.91. Three ICCs (land use mix diversity, land use mix access and aesthetics) were higher than 0.75 , indicating 
good reliability. The five other ICCs (residential density, street connectivity, infrastructure and safety for cycling, traffic hazards, and safety from crime) were between 0.59 and 0.72 , indicating moderate reliability. ICCs of the individual items ranged from 0.01 to 0.95 with the lowest scores for particular items of the scale infrastructure and safety for walking and cycling'. In total, reliability of 23 items was good, reliability of 43 items was moderate and reliability of 17 items was poor. However, the poor reliability scores were probably due to a lack of variance in the answers, as the proportion of agreement for the 17 items with low reliability was generally high $(>0.70$ for 15 out of 17 items with low ICC reliability). Overall, proportion of agreement for all individual items ranged from $55.1 \%$ to $96.1 \%$.

\section{Construct validity}

Results of the MANCOVA tests (Table 3) showed that adults living in high-walkable neighborhoods perceived higher residential density, more land use mix diversity, higher street connectivity, more traffic safety and more safety from crime. They also perceived higher activityfriendliness for the single items "parking near local shops is difficult", "I see and speak to other people while walking in the neighborhood", "streets are hilly" and "there are many canyons/hillsides in the neighborhood" than adults living in low-walkable neighborhoods. However, individuals living in low-walkable neighborhoods perceived their environment to have better infrastructure and safety for walking/cycling and to be more aesthetically pleasing than individuals living in high-walkable neighborhoods, which was expected because low-walkable areas are also higher in SES. Low-walkable neighborhood inhabitants had more favorable scores (i.e. perceptions of an activity-friendly environment) on the following single items: presence of cul-de-sacs and presence of unattended domestic animals. For land use mix access, no differences were found between high-walkable and low-walkable neighborhood residents.

\section{Concurrent validity}

Table 4 shows the correlations between the different environmental perceptions (scales and single items) and physical activity (IPAQ). All significant correlations were in the expected direction (i.e. perceived activity-friendliness of the neighborhood was associated with more physical activity), except for the association found between the 'aesthetics' subscale and walking for transportation. The single items were not strongly associated with the physical activity outcomes. The only significant items were, 'I see and speak to other people while walking in the neighborhood' and 'there are many unattended domestic animals in my

Table 3 Construct validity of Nigerian-NEWS differences in environmental perceptions between objective highwalkable and low-walkable neighborhoods $(\mathrm{N}=386)$

\begin{tabular}{|c|c|c|c|}
\hline Environmental perceptions & $\begin{array}{l}\text { High-walkable/low SES neighborhoods } \\
\qquad(\mathrm{n}=195) \text { mean (SD) }\end{array}$ & $\begin{array}{l}\text { Low-walkable/high SES neighborhoods } \\
\qquad(n=191) \text { mean (SD) }\end{array}$ & $\mathrm{F}$ \\
\hline Multivariate model & & & $67.7 * * *$ \\
\hline \multicolumn{4}{|l|}{ Environmental scales } \\
\hline Residential density & $363.0(110.8)$ & $256.8(67.8)$ & $72.2^{* * *}$ \\
\hline Land use mix diversity & $2.9(0.4)$ & $2.4(0.5)$ & $113.9^{* * *}$ \\
\hline Land use mix access & $2.8(0.5)$ & $2.9(0.6)$ & 1.4 \\
\hline Street connectivity & $3.0(0.9)$ & $2.6(0.7)$ & $12.5^{* *}$ \\
\hline Infrastructure and safety for walking/cycling & $1.9(0.3)$ & $2.1(0.4)$ & $28.5^{* * *}$ \\
\hline Aesthetics & $1.7(0.6)$ & $3.0(0.6)$ & $294.7^{* * *}$ \\
\hline Traffic safety & $2.6(0.4)$ & $2.3(0.3)$ & $40.0^{* * *}$ \\
\hline Safety from crime & $2.6(0.5)$ & $2.3(0.3)$ & $30.3^{* * *}$ \\
\hline \multicolumn{4}{|l|}{ Single items } \\
\hline Parking near local shops is difficult & $2.7(0.8)$ & $2.1(1.0)$ & $29.1^{* * *}$ \\
\hline Streets are hilly & $3.9(1.1)$ & $4.7(0.6)$ & $58.3^{* * *}$ \\
\hline Streets do not have many cul-de-sacs & $2.3(1.0)$ & $2.9(1.1)$ & $13.8^{* *}$ \\
\hline Many canyons/hillsides in neighborhood & $3.9(1.1)$ & $4.5(0.8)$ & $25.7^{* * *}$ \\
\hline $\begin{array}{l}\text { See and speak to other people while walking in } \\
\text { neighborhood }\end{array}$ & $3.4(0.7)$ & $2.1(1.1)$ & $148.2^{* * *}$ \\
\hline Many unattended domestic animals & $3.5(0.8)$ & $1.7(1.0)$ & $286.6^{* * *}$ \\
\hline
\end{tabular}

All analyses were adjusted for age, gender, income and educational level of the participants.

All environmental scales were positively scored, i.e. higher score $=$ more activity-friendly.

${ }^{* *} \mathrm{p}<0.01$, *** $\mathrm{p}<0.001$. 
Table 4 Predictive validity of Nigerian-NEWS: Pearson correlations between environmental perceptions and the long last seven day IPAQ $(\mathrm{N}=386)$

\begin{tabular}{|c|c|c|c|c|c|c|c|c|}
\hline Environmental scale & $\begin{array}{l}\text { Walking } \\
\text { transport }\end{array}$ & $\begin{array}{l}\text { Cycling } \\
\text { transport }\end{array}$ & $\begin{array}{c}\text { Total } \\
\text { transport }\end{array}$ & $\begin{array}{c}\text { Leisure time } \\
\text { walking }\end{array}$ & $\begin{array}{c}\text { Leisure time } \\
\text { MVPA }\end{array}$ & $\begin{array}{c}\text { Total leisure } \\
\text { time PA }\end{array}$ & $\begin{array}{r}\text { Total } \\
\text { MVPA } \\
\end{array}$ & $\begin{array}{c}\text { Total } \\
\text { PA }\end{array}$ \\
\hline Residential density & $0.11^{*}$ & $0.12^{*}$ & $0.15^{* *}$ & 0.02 & 0.01 & 0.01 & $0.21^{* * *}$ & $0.19^{* * *}$ \\
\hline Land use mix diversity & $0.25^{* * *}$ & $0.12^{*}$ & $0.28^{* * *}$ & $0.18^{* *}$ & 0.08 & $0.12^{*}$ & $0.28^{* * *}$ & $0.31^{* * *}$ \\
\hline Land use mix access & -0.01 & 0.01 & -0.01 & 0.07 & $0.17^{* *}$ & $0.17^{* *}$ & 0.06 & 0.05 \\
\hline Street connectivity & -0.03 & 0.04 & -0.01 & 0.05 & $0.16^{* *}$ & $0.16^{* *}$ & $0.19^{* * *}$ & $0.18^{* * *}$ \\
\hline $\begin{array}{l}\text { Infrastructure and safety for walking/ } \\
\text { cycling }\end{array}$ & -0.05 & 0.06 & -0.02 & $0.11^{*}$ & $0.22^{* * *}$ & $0.22^{* * *}$ & $0.13^{*}$ & 0.10 \\
\hline Aesthetics & $-0.11^{*}$ & 0.01 & -0.10 & 0.06 & $0.11^{*}$ & $0.11^{*}$ & -0.01 & -0.03 \\
\hline Traffic Safety & $0.11^{*}$ & -0.01 & 0.09 & $0.11^{*}$ & $0.14^{* *}$ & $0.16^{* *}$ & $0.21^{* * *}$ & $0.23^{* * *}$ \\
\hline Safety from crime & -0.03 & $0.12^{*}$ & 0.03 & 0.09 & 0.05 & 0.06 & $0.15^{* *}$ & $0.15^{* *}$ \\
\hline \multicolumn{9}{|l|}{ Single items } \\
\hline Parking near local shops is difficult & 0.08 & -0.06 & 0.05 & -0.08 & 0.01 & -0.02 & 0.05 & 0.08 \\
\hline Streets are hilly & 0.01 & -0.01 & 0.01 & -0.01 & -0.04 & -0.04 & -0.07 & -0.08 \\
\hline Streets do not have many cul-de-sacs & -0.01 & 0.02 & -0.02 & -0.03 & -0.06 & -0.06 & 0.01 & 0.02 \\
\hline Many canyons/hillsides in neighborhood & 0.01 & -0.03 & 0.01 & -0.02 & -0.08 & -0.07 & -0.07 & -0.07 \\
\hline $\begin{array}{l}\text { See and speak to other people while } \\
\text { walking in neighborhood }\end{array}$ & $0.14^{* *}$ & 0.01 & $0.13^{*}$ & 0.07 & -0.03 & 0.01 & $0.15^{* *}$ & $0.18^{* *}$ \\
\hline Many unattended domestic animals & $0.26^{* * *}$ & 0.03 & $0.24^{* * *}$ & 0.06 & -0.09 & -0.05 & $0.15^{* *}$ & $0.21^{* * *}$ \\
\hline
\end{tabular}

$\mathrm{PA}=$ physical activity, MVPA = moderate-to-vigorous physical activity.

All environmental scales were positively scored, i.e. higher score $=$ more activity-friendly.

${ }^{*} \mathrm{p}<0.05$, ** $\mathrm{p}<0.01$, *** $\mathrm{p}<0.001$.

neighborhood'. For the single item 'presence of domestic animals', the correlations were not in the expected direction (more unattended animals was associated with more physical activity). The size of all significant correlations ranged between 0.10 and 0.31 , indicating low-to-moderate validity. Residential density, land use mix diversity, and traffic safety had significant correlations with most of the physical activity outcomes. As expected, land use mix diversity was more strongly related to transport activity than leisure time activity, and aesthetics was more strongly related to leisure time activity than transport activity. Significant correlations with environmental perceptions were found most often for MVPA and total physical activity.

\section{Discussion}

This study evaluated aspects of reliability and validity of the adapted NEWS measure in Nigeria. The findings generally indicated acceptable test-retest reliability and construct validity, and low-to-moderate concurrent validity for subscales of NEWS-Nigeria. The test- retest reliability values (ICC $=0.59$ to 0.91 ) reported for the NEWS subscales in the present African study are comparable to those reported for the original version in the USA (ICC $=0.58$ to 0.80 ) [24], the Australian version (ICC $=0.62$ to 0.88 ) [33] and the Chinese translation of the abbreviated version (ICC $=0.57$ to 0.99) [25]. Comparable to the pattern of findings in the USA and
Australian studies, the subscales on aesthetics, and walking and cycling infrastructures, demonstrated respectively the highest and lowest reliability coefficients in the Nigerian version of NEWS. It is possible that NEWS items that pertain to aesthetics and pleasantness of the environments are ubiquitously more stable than those that focus on neighborhood infrastructures for walking and cycling, regardless of developmental pattern and differences across countries. Perhaps there are ambiguities in what constitutes a sidewalk and bicycle facility, as well as their qualities, that contribute to lower reliability of the infrastructure scale.

Very low reliability coefficients were found for some of the items of the Nigerian version of NEWS: "curb cut ramps from sidewalks to road", "crosswalk and pedestrian signals are available", "pedestrian signals gives enough time to cross street" and "crosswalks are safe". These items assessed features of infrastructures and safety for walking and cycling that are not common in most Nigerian neighborhoods. Although the uncommon items may be omitted when using the adapted NEWS in Nigeria, it is recommended to retain these items as part of the Nigerian version because items like pedestrian signals can become indicators of progress that would be difficult to measure in future if these items were deleted. Retaining these items is also essential for comparing these attributes across countries. The little variability 
observed in the responses to these items from our sample likely accounted for the low reliability for the items. Nevertheless, the majority of the items on the Nigerian version of NEWS, including most of the newly-developed items, demonstrated moderate to high reliability coefficients, comparable to those found in other studies $[18,24,25,33]$.

Statistically significant differences were found in the ratings of environmental features between residents living in high- and low-walkable neighborhoods for all the subscales $(\mathrm{p}<0.001)$ of NEWS-Nigeria except for landuse mix access, indicating that residents from neighborhoods with different characteristics in Nigeria do perceive their environments differently. Because the neighborhoods were selected to be environmentally different based on the criteria of observed residential density, land use mix and street connectivity, finding that residents of the high-walkable neighborhoods perceived environmental attributes that focus on residential density, land use mix diversity and street connectivity better than residents of low-walkable neighborhood provides evidence of construct validity for NEWS-Nigeria. This result is consistent with findings from the developed countries where these traditional components of walkability are usually rated higher by residents of highwalkable neighborhoods than those of low-walkable neighborhoods $[24,33]$.

Unlike in studies from western developed countries where traffic safety and safety from crime were often not rated differently between neighborhoods [24,33], residents of high-walkable neighborhoods in this African study significantly perceived their neighborhood to have better traffic safety and to be more safe from crime than residents of low-walkable neigborhoods. This finding seems important because the high-walkable neighborhoods in the study were low SES, and still people perceived more traffic and crime safety in these neighborhoods than the low-walkable/high SES neighborhoods. This pattern could suggest differences in expectations about traffic safety and safety from crime between residents of low and high walkable neighborhoods in Nigeria. It is possible that people from high SES neighborhoods could be more 'demanding' about what is safe for them. However, this finding could just be a reflection of the general and pervasive insecurity in Nigeria. Perhaps, insecurity from traffic and crime was more pronounced to those living in the low-walkable /high SES neighborhoods than those in high- walkable/ low SES neighborhoods at the time of the study.

It is not surprising that low-walkable neighborhoods had higher scores on the subscales on aesthetics and infrastructures for walking and cycling. Low walkable neighborhoods in Nigeria are high in SES and are often found in GRA/new layout areas with more facilities (paved and maintained sidewalks and roads, streets well lit at night) for walking and cycling, and generally have better aesthetic qualities (scenic view, attractive buildings, free from litter) compared to high walkable neighborhoods that are often found in inner cities (low SES areas) with limited infrastructures for walking and cycling, and poor aesthetic qualities [46]. Overall, the significant differences found for the subscales and all single items of the adapted NEWS, suggested the measure is sensitive to discriminate between different neighborhood environment attributes in Nigeria, and provide strong support for its construct validity $[24,33]$.

The mean values for land-use mix access, street connectivity and traffic safety in both the high- and lowwalkable neighborhoods in the present Nigerian study were comparable to those in the studies conducted in the USA [24] and Australia [33]. This finding perhaps, reinforces the suggestion that some consistency exists in the use of the NEWS to measure walkability attributes between neighborhoods across metropolitan areas in different countries [33]. It is generally expected that housing patterns, transportation infrastructures and stage of urban development in Africa will be different from those in the western high income countries. Therefore, finding that the mean values for residential density in both neighborhood types were higher in Nigeria, and the mean values for land use mix diversity, infrastructure for walking and cycling, and aesthetic qualities (high-walkable neighborhood only) were lower in the present study compared to the USA [24] and Australian [33] studies is not surprising. African urban environments are generally denser in terms of population, have congested streets with a lot of air pollution, have limited infrastructures for active transportation and may be less aesthetically pleasant compared to those of the developed high income countries.

Most scales on NEWS-Nigeria had correlations in the expected direction with multiple physical activity outcomes. Residential density, land use mix diversity, and traffic safety were correlated with the most physical activity measures. Consistent with domain-specific models of physical activity [12,53], land use mix diversity was more highly correlated with active transport and aesthetics was more highly correlated with leisure time activity in the present study. Walking and cycling infrastructure had inconsistent correlations across physical activity domains in the literature [10,13-15], but in the present study was correlated with the active leisure domain. Contrary to expectations [24], street connectivity was correlated with leisure activity instead of transport activity. Previous studies from Nigeria have also reported inconsistent associations of street connectivity with physical activity outcomes [22,54]. Perhaps, the concept of street connectivity as espoused in the international 
literature is not an important component of neighborhood walkability relevant to active transportation in Nigeria.

The crime safety scale has an inconsistent record of association with physical activity in the literature [10,13-15], but it was correlated with total physical activity outcomes in the present study. Three previous studies from Nigeria consistently found perception of neighborhood safety from crime to be positively associated with both objective moderate-to-vigorous physical activity, self-reported walking, and body weight status $[22,41,55]$. Thus, evidence is accumulating that crime safety perceptions are an important correlate of physical activity among Nigerian adults.

An important finding was that most of the scales and two of the items on NEWS-Nigeria were relatively strongly correlated with leisure time MVPA, total MVPA and total physical activity. Because guidelines for sufficient health-enhancing physical activity are often based on leisure time MVPA and total physical activity [43-45], these findings indicate that perceived activity-friendliness of the neighborhood as assessed by the subscales of NEWS-Nigeria was associated with more health-related physical activity. This is somewhat consistent with recent findings from developing countries that favorable environmental constructs including those assessed by the NEWS are associated with more leisure time MVPA, total MVPA and total physical activity [56-58]. These findings suggest neighborhood environment features are important to health behaviors of adults in developing countries. However, the relatively strong associations of most NEWS subscales and items with total MVPA and total physical activity in the present study could be due to the influence of confounding factors like inclusion of occupational and household activities in estimates of total MVPA and total physical activity. Occupational and household activities are likely higher in the high walkable neighborhoods that are typically of low SES in the current study. Thus, correlations of NEWS-Nigeria scales with total PA and MVPA may be overestimated.

Although the correlations of the adapted NEWS variables with physical activity were often significant, they were low. However, observed correlations were comparable with other studies that assessed the NEWS and other environmental questionnaires [18,30,59]. For example, in a study of US adults, significant correlations of NEWS subscales with walking for transport and walking for leisure varied from 0.08 to 0.29 [27], which was comparable to the range of 0.11 to 0.28 with walking for transport and leisure in the present study. Thus, correlations of neighborhood environment variables and physical activity are surprisingly similar in the US and Nigeria. Replicating this pattern of findings in Nigeria supports a conclusion that some environmental constructs assessed by NEWS are generalizable across continents. Perhaps some NEWS subscales are able to assess environmental variables in relation to physical activity similarly across countries regardless of developmental patterns and cultural differences. Findings such as these have international implications for utility and robustness of NEWS measures as important for identifying promising environmental variables that could be manipulated for improving physical activity and controlling obesity worldwide. Use of adapted versions of the NEWS may be particularly important for research in low-income and developing countries that do not have geographic information systems databases that would allow objective measures of environmental attributes.

The present study has some important limitations. First, conducting the study among residents of two neighborhood types from only two cities in Nigeria may restrict environmental variability. Restricted variability could underestimate the strengths of environment-physical activity associations in environmental studies [16,29]. Second, the modest sample size and the non-probability nature of the sample may reduce generalizability of findings. A third limitation was that neighborhood SES in the two cities was confounded with walkability, making it impossible to conclude that the environmental differences are independent of SES. Although individual SES was adjusted for in some analyses, neighborhood level SES can have an important influence on the differences in environmental perceptions between high- and low-walkable neighborhoods. Thus the findings that most environmental subscales assessed by NEWS were associated with more leisure time MVPA, total MVPA and total physical activity in the present study should be interpreted with caution because it is possible that neighborhood SES rather than neighborhood environmental factors accounted for these relatively strong associations.

A strength of the study was the recruitment of participants from two distinct neighborhood types, enhancing heterogeneity in sociodemographics and built environments [53]. Another strength was the systematic adaptation of the NEWS, retaining most of the original items to allow for international comparison while tailoring the measure to reflect Africa-specific conditions. NEWSNigeria was developed through regional collaborations similar to those used for the ALPHA questionnaire that was tailored to Europe [35], and was based on empirical evidence and cross-validation of confirmatory factor analysis with existing NEWS measures. The present study supports the feasibility of using NEWS-Nigeria for assessing environmental correlates of physical activity in the African region and can provide leads and guidance to researchers and practitioners in other African countries when evaluating the built environment for health behaviours. Because a major goal of IPEN is to represent the worldwide variation in built environment, 
conducting the present study in an understudied African region like Nigeria adds to the international literature on worldwide relevance of built environment for promoting physical activity. The present study was the first to report on the psychometric properties of the NEWS in the African region, and suggests the need to create an Africa-wide version of NEWS that can be used within different populations and settings across Africa.

\section{Conclusion}

In summary, this study showed that NEWS-Nigeria has acceptable evidence of reliability and construct validity, and moderate evidence of concurrent validity. This finding is particularly important for health promotion in sub-Sahara Africa because chronic disease rates are rising in the region $[1,2,60]$. Understanding environmental correlates of physical activity is a priority that could lead to better strategies to prevent further declines in physical activity and support increased physical activity among those already inactive in sub-Sahara Africa. Thus, the development of culturally applicable NEWS measures for Africa could support evidence based interventions against the epidemics of inactivity-related non-communicable diseases in the African region. For example, present findings suggest that higher density, mixed use planning and transportation policies that favor active transport could play important roles preventing non-communicable diseases in Africa, similar to health-related recommendations for more developed countries $[7,10,61]$. Further adaptation and evaluation of the NEWS in other African countries could lead to evidence-based recommendations for creating betterdesigned and safer communities that make people more comfortable being physically active in the African region.

\section{Competing interests}

Authors declare there is no competing financial interest associated with this study.

\section{Authors' contributions}

ALO contributed to conception and design of the study, drafted the manuscript, was responsible for data acquisition and preparation and was involved with interpretation of data. JFS contributed to conception and design and critically revised the drafted manuscript for important intellectual content. AYO was involved with study design, acquisition of data and critically revised the manuscript for important intellectual contents. BD and IDB participated in the design of the study, interpretation of data and critically revised the drafted manuscript for important intellectual content. DVD contributed to study design, conducted the statistical analysis and interpretation of data and helped to draft the manuscript. All authors read and approved the final manuscript.

\section{Acknowledgements}

The authors would like to thank Drs Rufus A Adedoyin, Vickie E Lambert, Vincent Onywera, Tracy Kolbe-Alexander, Jacqueline Kerr, Terry Conway, Nicole Bracy and Kelli Cain for their involvement in the adaptation process of the version of the NEWS measure that was evaluated in this study. We would also thank Bolaji Oyeyemi, Samson Ayodeji, Umar Bello, Saratu Philemon and Fatima Oyedoyin for their help in data gathering in Ilorin and Maiduguri.

\section{Author details}

'Department of Physiotherapy, College of Medical Sciences, University of Maiduguri, Maiduguri, Nigeria. ${ }^{2}$ Department of Movement and Sports Sciences, Faculty of Medicine and Health Sciences, Ghent University, Ghent, Belgium. ${ }^{3}$ Department of Family \& Preventive Medicine, University of California, San Diego, USA. ${ }^{4}$ Department of Biometry and Biomechanics, Faculty of Physical Education and Physiotherapy, Vrije Universiteit Brussels, Brussels, Belgium. ${ }^{5}$ Research Foundation Flanders, Brussels, Belgium.

Received: 24 November 2012 Accepted: 11 March 2013

Published: 21 March 2013

\section{References}

1. Ezzati M, Lopez A, Rodgers A, Murray C: Comparative quantification of health risks: Global and regional burden of disease due to selected major risk factors. Geneva: World Health Organization; 2005:729-881.

2. Lee IM, Shiroma EJ, Lobelo F, Puska P, Blair SN, Katzmarzyk PI, for the Lancet physical activity series working group: Effect of physical inactivity on major non-communicable diseases worldwide: an analysis of burden of diseases and life expectancy. Lancet 2012, 380:219-229.

3. Kohl HW 3rd, Criag CL, Lambert EV, Inoue S, Alkandari JR, Leetongin G, Kahlmeier S, for the Lancet physical activity series working group: The pandemic of physical inactivity: global action for public health. Lancet 2012, 380:294-305.

4. United Nations General Assembly: Political declaration of the high-level meeting of the general assembly on the prevention and control of noncommunicable diseases. Sep 16, 2011. Available at: http://www.un.org/ga/ search/view_doc.asp?symbol=A/66/L.1 (accessed February 21, 2013).

5. World Health Assembly 57.17: Global strategy on diet and physical activity. Geneva: World Health Organisation; 2004.

6. US Department of Health and Human Services: The surgeon general's call to action to prevent and decrease overweight and obesity. Rockville, MD: U.S. Department of Health and Human Services, Public Health Services; 2001.

7. Global Advocacy for Physical Activity (GAPA), the Advocacy Council of the International Society for Physical Activity and Health (ISPAH): Non communicable disease prevention: Investments that work for physical activity. A complementary document to the Toronto charter for physical activity: a global call to action. 2011. Available at: http://www.phaiwa.org.au/ publications-mainmenu-125/advocacy-toolkit-mainmenu-143 (accessed February 23, 2013).

8. Public Health Advocacy Institute of Western Australia: Advocacy in Action: a toolkit for Public Health Professionals. Perth, Western Australia: Public Health Advocacy Institute of Western Australia; 2008. Available at: http://www. phaiwa.org.au/index.php/publications-mainmenu-125/advocasy-toolkitmainmenu-142 (accessed February 21, 2013).

9. Martin BW, Kahlmeier S, Racioppi F, Berggren F, Miettinen M, Oppert JM, Rutter H, Slachta R, van Poppel M, Zakotnik JM, Meusel D, Oja P, Sjöström M: Evidence-based physical activity promotion - HEPA Europe, the European network for the promotion of health-enhancing physical activity. J Public Health 2006, 14:53-57.

10. Heath G, Brownson R, Kruger J, Miles R, Powell KE, Ramsey LT, the Task Force on Community Preventive Services: The effectiveness of urban design and land use and transport policies and practices to increase physical activity: A systematic review. J Phys Act Health 2006, 3(suppl. 1):S55-S76.

11. Sallis JF, Owen N, Fisher EB: Ecological models of health behavior. In Health Behavior and Health Education: Theory, Research, and Practice. 4th edition. Edited by Glanz K, Rimer BK, Viswanath K. San Francisco: JosseyBass; 2008:465-486.

12. Sallis JF, Cervero R, Ascher WW, Henderson K, Kraft MK, Kerr J: An ecological approach to creating active living communities. Annu Rev Public Health 2006, 27:14.1-14.26.

13. Gebel K, Bauman AE, Petticrew M: The physical environment and physical activity: a critical appraisal of review articles. Am J Prev Med 2007, 32:361-369.

14. Saelens BE, Handy $S L$ : Built environment correlates of walking: a review. Med Sci Sports Exerc 2008, 40(7):S550-566.

15. Owen N, Humpel N, Leslie E, Bauman A, Sallis JF: Understanding environmental influences on walking: review and research agenda. Am J Prev Med 2004, 27:67-76. 
16. Sallis JF, Bowles $H R$, Bauman $A$, Ainsworth $B E$, Bull $F C$, Craig $C L$, Sjöström $M$, De Bourdeaudhuii I, Lefevre J, Matsudo V, Matsudo S, Macfarlane DJ, Gomez LF, Inoue S, Murase N, Volbekiene V, McLean G, Carr H, Heggebo LK, Tomten $\mathrm{H}$, Bergman P: Neighborhood environments and physical activity among adults in 11 countries. Am J Prev Med 2009, 36:484-490.

17. Sallis JF, Adams MA, Ding D: Physical activity and the built environment In The Oxford Handbook of the Social Science of Obesity. Edited by Cawley J. New York: Oxford; 2011:433-51

18. De Bourdeaudhuij I, Sallis JF, Saelens BE: Environmental correlates of physical activity in a sample of Belgian adults. Am J Health Promot 2003, 18:83-92.

19. Van Dyck D, Deforche B, Cardon G, De Bourdeaudhuij I: Neighborhood walkability and its particular importance for adults with a preference for passive transport. Health Place 2009, 15:496-504.

20. Bauman AE, Reis RS, Sallis JF, Wells JC, Loos RJF, Martin BW, on behalf of the Lancet Physical Activity Series Working Group: Correlates of physical activity: Why are some people physically active and others not? Lancet 2012, 380:31-44

21. Kerr J, Sallis JF, Owen N, De Bourdeaudhuij I, Cerin E, Reis R, Sarmiento O, Frömel K, Mitáśs, Troelsen J, Christiansen LB, Macfarlane D, Salvo D, Schofield G, Badland H, Guillen-Grima F, Aguinaga-Ontoso I, Davey R, Bauman A, Saelens BE, Riddoch C, Ainsworth B, Pratt M, Schmid T, Frank LD, Adams MA, Conway TL, Cain K, Van Dyck D, Bracy B: Advancing Science and Policy through a Coordinated International Study of Physical Activity and Built Environments: IPEN Methods. J Phys Act Health. In Press.

22. Oyeyemi AL, Adegoke BOA, Oyeyemi AY, Sallis JF: Perceived environmental correlates of physical activity and walking in African young adults. Am J Health Promot 2011, 25(5):e10-e19.

23. Hallal PC, Andersen LB, Bull FC, Guthold R, Haskell W, Ekelund U, for the Lancet Physical Activity Series Working Group: Global physical activity levels: surveillance progress, pitfalls, and prospects. Lancet 2012, 380:247-257.

24. Saelens BE, Sallis JF, Black JB, Chen D: Neighborhood-based differences in physical activity: and environmental scale evaluation. Am J Public Health 2003, 93:1552-1558.

25. Cerin E, Macfarlane DJ, Ko HH, Chan KCA: Measuring perceived neighborhood walkability in Hong Kong. Cities 2007, 24:209-217.

26. Cerin E, Leslie E, Owen N, Bauman A: An Australian version of the Neighborhood Environment Walkability Scale: validity evidence. Meas Phys Educ Exerc Sci 2008, 12:31-51.

27. Shigematsu R, Sallis JF, Conway TL, Saelens BE, Frank LD, Cain KL, Chapman $J E$, King AC: Age differences in relation of perceived neighborhood environment to walking. Med Sci Sports Exerc 2009, 41:314-321.

28. de Melo LL, Menec V, Porter MM, Ready AE: Personal factors, perceived environment, and objectively measured walking in old age. J Aging Phys Act 2010, 18:280-291.

29. Van Dyck D, Cerin E, Conway TL, De Bourdeaudhuij I, Owen N, Kerr J, Cardon G, Frank LD, Saelens BE, Sallis JF: Perceived neighborhood environmental attributes associated with adults' transport-related walking and cycling: Findings from the USA, Australia, and Belgium. Int J Behav Nutr Phys Act 2012, 9:70.

30. Cerin E, Saelens BE, Sallis JF, Frank LD: Neighborhood environment walkability scale: validity and development of a short form. Med Sci Sports Exerc 2006, 38:1682-1691.

31. Cerin E, Conway TL, Saelens BE, Frank LD, Sallis JF: Cross-validation of the factorial structure of the Neighborhood Environment Walkability Scale (NEWS) and its abbreviated form (NEWS-A). Int I Bevah Nutr Phys Act 2009, 6:32.

32. Cerin E, Sit CHP, Cheung M, Ho S, Lee LJ, Chan W: Reliable and valid NEWS for Chinese seniors: measuring perceived neighborhood attributes related to walking. Int I Bevah Nutr Phys Act 2010, 7:84

33. Leslie E, Saelens B, Frank L, Owen N, Bauman A, Coffee N, Hugo G Residents perceptions of walkability attributes in objectively different neighborhoods: a pilot study. Health Place 2005, 11:227-236.

34. Malavasi LD, Duarte MDD, Both J, Reis RS: Neighborhood walkability scale (NEWS- Brazil): Back translation and reliability. Rev. Bras. Cineanthropom. Desempenho Hum. 2007. 9:339-350

35. Spittaels H, Foster C, Oppert J, Rutter H, Oja P, Sjöström M, De Bourdeaudhuij I: Assessment of environmental correlates of physical activity: development of a European questionnaire. Int J Bevah Nutr Phys Act 2009, 6:39.
36. Harrendforf S, Heiskanen M, Maldy S (Eds): International statistics on crime and justice. European Institute for Crime Prevention and Control, Affiliated with the United Nations (HEUNI), Helsinki. Vienna: United Nations Office on Drug and Crime (UNODC); 2010

37. National Bureau of Statistics: Statistical Fact Sheet, 2008. Federal Republic of Nigeria. Available at: http://www.nigerianstat.gov.ng/ (accessed January 25, 2011).

38. Saelens BE, Sallis JF, Frank LD: Environmental correlates of walking and cycling: Findings from the transportation, urban design, and planning literatures. Annal of Behavioral Medicine 2003, 25:80-91.

39. Frank LD, Sallis JF, Saelens BE, Leary L, Cain K, Conway TL, Hess PM: The development of a walkability index: Application to the Neighborhood Quality of Life Study. B J Sports Med 2010, 44:924-933.

40. National Population Commission of Nigeria: Nigeria Demographics and Health Survey 2003. Calverton, Md: National Population Commission and ORC Macro; 2004.

41. Oyeyemi AL, Sallis JF, Adegoke BOA, Oyeyemi AY, De Bourdeaudhuij I: Perception of neighborhood safety is related with physical activity among adults in Nigeria. BMC Publ Health 2012, 12:294.

42. Cohen JA: Statistical Power Analysis for the Behavioural Sciences. 2nd edition Hillsdale, NJ: Lawrence Erlbaum Associates; 1988

43. World Health Organization: Global recommendations on physical activity for health. Geneva, Switzerland: WHO; 2010

44. Haskell WL, Lee I-M, Pate RP, Powell KE, Blair SN, Franklin BA, Macera CA, Heath GW, Thompson PD, Bauman A: Physical activity and public health: updated recommendation for adults from the American College of Sports Medicine and the American Heart Association. Circulation 2007, 116:1081-1093.

45. DHHS- Guidelines Expert Report: Department of Health and Human Services. Available at: http://www.health.gov/paguidelines/guidelines/default.aspx. (accessed June 18, 2009).

46. Oyeyemi AL, Sallis JF, Oyeyemi AY, Mahmud-Amin M, De Bourdeaudhuij I, Deforche B: Adaptation, test-retest reliability, and construct validity of the physical activity neighborhood environment scale in Nigeria. J Phys Act Health. in press.

47. Craig CL, Marshall AL, Sjostrom M, Bauman AE, Booth ML, Ainsworth BE, Pratt M, Ekelund A, Yngve A, Sallis JF, Oja P: International Physical Activity Questionnaire: 12 country reliability and validity. Med Sci Sports Exerc 2003, 35:1381-1395.

48. Vandelanotte C, De Bourdeaudhuij I, Philippaerts R, Sjöström M, Sallis J: Reliability and validity of a computerized and Dutch version of the international physical activity questionnaire (IPAQ). J Phys Act Health 2005, 2:63-75.

49. World Health Organization: Obesity: Preventing and Managing the Global Epidemic. WHO Technical Report Series 894 2000. World Health Organization; 2000. Available at: http://whqlibdoc.who.int/trs/WHO_TRS_894.pdf. (accessed February 27, 2012).

50. Portney L, White M: Foundations of clinical research. Applications to practice. New Jersey: Pearson Education Inc; 2009

51. Fleiss J: Statistical methods for rates and proportions. New York: Wiley; 1981.

52. World Health Organization: WHO global infobase. Data for saving lifes. World Health Organization; 2010. Available at: https://apps.who.int/infobase/. (accessed August 02, 2012).

53. Giles-Corti B, Timperio A, Bull F, Pikora T: Understanding physical activity environmental correlates: increased specificity for ecological models. Exerc Sports Sci Rev 2005, 33(4):175-181.

54. Oyeyemi AL, Deforche B, Sallis JF, De Bourdeaudhuij I, Van Dyck D: Behavioral mediators of the association between neighborhood environment and weight status in Nigerian adults. Am J Health Promot. in press.

55. Oyeyemi AL, Adegoke BOA, Oyeyemi AY, Deforche B, De Bourdeaudhuij I, Sallis JF: Environmental factors associated with overweight among adults in Nigeria. Int J Behav Nutr Phys Act 2012, 9:32.

56. Parra DC, Hoehner CM, Hallal PC, Ribero RC, Reis R, Brownson RC, Pratt M, Simoes EJ: Perceived environmental correlates of physical activity for leisure and transportation in Curitiba, Brazil. Prev Med 2011, 52:234-238.

57. Hallal PC, Reis RS, Parra DC, Hoehner C, Brownson RC, Simoes EJ: Association between perceived environmental attributes and physical activity among adults in Recife. Brazil. J Phys Act Health 2010, 7(25):S213-5222 
58. Hino AAF, Reis RS, Sarmiento OL, Parra DC, Brownson RC: The built environment and recreational physical activity among adults in Curitiba, Brazil. Prev Med 2011, 52:419-422.

59. Spittaels H, Verloigne M, Gidlow C, Gloanec J, Titze S, Foster C, Oppert J, Rutterv H, Oja R, Sjostrom M, De Bourdeaudhuij I: Measuring physical activity-related environmental factors: reliability and predictive validity of the European environmental questionnaire ALPHA. Int I Behav Nutr Phys Act 2010, 7:48.

60. World Health Organization: Regional Committee for Africa. Diseases in the African region: current situation and perspective. Maputo: World Health Organization; 2005.

61. Handy S, Clifton K: Planning and the built environment: implications for obesity prevention. In Handbook of obesity prevention. A resource for health professionals. Edited by Kumanyika S, Brownson R. New York: Springer; 2007:167-188

doi:10.1186/1476-072X-12-16

Cite this article as: Oyeyemi et al:: Evaluation of the neighborhood environment walkability scale in Nigeria. International Journal of Health Geographics 2013 12:16

\section{Submit your next manuscript to BioMed Central and take full advantage of:}

- Convenient online submission

- Thorough peer review

- No space constraints or color figure charges

- Immediate publication on acceptance

- Inclusion in PubMed, CAS, Scopus and Google Scholar

- Research which is freely available for redistribution 